\title{
Effects of Mobile Phase Composition as a Function of Temperature on Isocratic Elution Behavior of $\beta$-carotene in Revered-Phase Liquid Chromatographic Systems
}

\author{
Charuwan Khamkaew \\ Program of Chemistry, Faculty of Science and Technology, Songkhla Rajabhat University, Muang District, Songkhl \\ Province 90000, Thailand \\ Email: csuitcharit@gmail.com
}

\begin{abstract}
Objective: The objective of this research was to study the retention behavior of $\beta$-carotene under isocratic elution by reversed-phase high performance liquid chromatography (RP-HLPC) for describing its elution behavior. Method: The reversed-phase chromatographic elution systems were performed using binary mobile phase comprising 2-propanol in methanol at different volume fractions $(\psi)$ under the designed temperatures at 25 and 35 ${ }^{\circ} \mathrm{C}$. In this study, the obtained chromatographic parameters, i.e. retention factor $(k)$ and reciprocal retention factor $(1 / k)$ were calculated to provide the plots for describing the elution behavior. Results: From this study, the exponential dependency of $k$ on $\psi$, and linear dependency of $1 / k$ on $\psi$ were plotted. From linear plot, the derived chromatographic parameters, i.e. slope (S) and extrapolated y-intercept (1/ko) were also considered. The larger value of correlation coefficient $(\mathrm{r} 2)$ from the linear plot at $35^{\circ} \mathrm{C}(\mathrm{r} 2=0.9922)$ has been obtained with the comparison of $\mathrm{r} 2$ at $25^{\circ} \mathrm{C}(\mathrm{r} 2=$ 0.9783). These findings thus have recommended that the elution behavior of $\beta$-carotene using 2-propanol in methanol at $\psi=0.25 \%$ was able to elute $\beta$-carotene successfully with the faster elution at $35 \mathrm{oC}$ evidently.Conclusion: The elution behavior of $\beta$-carotene under its partition between the binary mobile phases and immobilized n-alkyl chains in stationary phase was depended on the polarity of mobile phase as a function of temperature used. These results will be useful for predicting and controlling the elution behavior of $\beta$-carotene under isocratic RP-HPLC system.
\end{abstract}

Index Terms- $\beta$-carotene, 2-propanol methanol, isocratic elution, RP-HPLC

\section{INTRODUCTION}

Reversed-phase high performance liquid chromatography (RP-HPLC) is one of the most popular and useful analytical techniques [1]-[13]. It may perform under different elution conditions; isocratic elution and gradient elution. For isocratic elution conditions, the $\mathrm{k}$ value is a widely used parameter in RP-HPLC due to using for the prediction of retention behavior of the solute under various chromatographic environments. Generally,

Manuscript received January 16, 2017; revised June 30, 2017. $\mathrm{k}$ value takes a dependency as a function of various chromatographic parameters, i.e. the column temperature (T), the $\mathrm{pH}$ of the mobile phase, and the $\psi$ value of the organic modifier of this phase [1-3]. The relationship between $\mathrm{k}$ and $\psi$ values at a defined $\mathrm{T}$ over narrow range of $\psi$ values $(\psi \leq 0.25 \%)$ usually takes the exponential dependency which its shape depends on the nature of organic modifier in mobile phase as well as the molecular characteristics of the analytes [2]-[5]. With the following plot of log k vs. $\psi$, it can be approximated as a linear dependency at such range of $\psi$ values $[2,4-5,13]$ at a defined $\mathrm{T}$.

The RP-HPLC using isocratic and/or gradient elution has been widely used for the separation and determination of $\beta$-carotene. Indeed, $\beta$-carotene was an interested compound of carotenoids because of its provitamin A activity in the affected foods to its physiological effect such as anti-cancer and antioxidative actions on human body [6]. Several HPLC works have reported $\beta$-carotene in various objectives for example, the separation the main isomers of $\beta$-carotene, i.e. all-trans, 9 -cis and 3-cis $\beta$-carotene present in foods to be imperative in assessing the fate of these compounds during food processing and/or storage [7], its physiological effect acted in human body [8]-[11], and the amounts of $\beta$-carotene present in various samples [6][11] but they have not emphasized on reporting its retention behavior under the defined conditions. Surprisingly, few works have examined in the retention behavior of $\beta$-carotene [3], [12] under isocratic elution condition in RP-HPLC systems. Therefore, in this study the isocratic elution behavior of $\beta$-carotene has been investigated under the effect of mobile phase compositions as a function of temperatures. The $\beta$ carotene was selected because it can be eluted over a range of different concentrations of organic solvent under RP-HPLC systems. As such, $\beta$-carotene provides a role model for its interaction with the immobilized n-alkyl chains in reversed phase under different temperatures when mobile phase compositions comprising 2-propanol in methanol were adjusted. From these isocratic data, the values of $\mathrm{k}$ and $1 / \mathrm{k}$ were calculated and the results 
obtained were taken into the plot versus $\psi$ values. In addition, the derived chromatographic parameters, i.e. $\mathrm{S}$ and $1 /$ ko obtained from the plots were also considered.

\section{MATERIALS AND METHODS}

\section{A. Reagents and Lab Wares}

All chemicals used for organic solvents were of HPLC grade. Methanol, 2-propanol and hexane were purchased from RCI Labscan (Thailand). $\beta$-carotene (AR grade) was purchased from Sigma Company (USA). A $0.45-\mu \mathrm{m}$ of Sartolon polyamide membrane filters used for mobile phase filtration was purchased from Sartorius Stedim, biotech, GmbH (Germany).

The different designed $\psi$ values $(\% \mathrm{vol} \times 10-2)$ [5], i.e. $0,0.05,0.10,0.15,0.20$, and $0.25 \%$ of 2-propanol in methanol were prepared. All mobile phases were filtered through a $0.45-\mu \mathrm{m}$ Sartolon polyamide filter and degassed by sonication prior to use. A $400-\mathrm{mg} / \mathrm{L}$ of $\beta$ carotene was prepared by dissolving a $0.0100 \mathrm{~g}$ of $\beta$ carotene in hexane and made up to volume of $25 \mathrm{~mL}$. This solution was kept in darken bottle at 4 oC for 1 month. Test solution of a $10-\mathrm{mg} / \mathrm{L}$ of $\beta$-carotene was prepared by diluting an appropriate volume of a 400 $\mathrm{mg} / \mathrm{L}$ of $\beta$-carotene with hexane for the desired volume and it was prepared fresh as needed. The chemical structure of $\beta$-carotene is presented in Fig. 1.

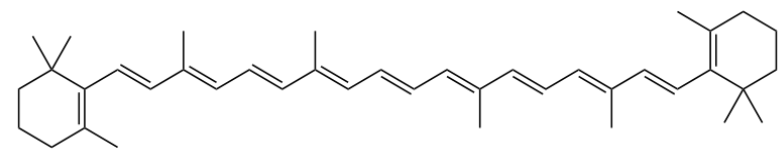

Figure1. Chemical structure of $\beta$-carotene

\section{B. Apparatus}

Reversed-phase elution systems were run on Shimadzu (Japan) high performance liquid chromatograph controlled by SCL-10Avp system and equipped with LC10ADvp pump, SPD-M10Avp detector, and CTO-10Avp column oven. The column of C-18 $(250 \times 4.6 \mathrm{~mm})$ purchased from Phenomenex (USA) and packed with 5 $\mu \mathrm{m}$ Luna, 100A was used. A $50-\mu \mathrm{L}$ of syringe perfection was purchased from SGE (Australia).

\section{Recommended Procedure}

The isocratic elution by HPLC was performed at flowrate of $1.5 \mathrm{~mL} / \mathrm{min}$, the wavelength fixed at $445 \mathrm{~nm}$, and the column temperatures kept at 25 and 35 oC. A $20-\mu \mathrm{L}$ sample volume was injected into the system. A 3replicated injection of sample for the elution with each mobile phase was done throughout.

\section{Analysis of Experimental Data}

Chromatographic retention data obtained was converted into the corresponding $\mathrm{k}$ value using the following conventional equation:

$$
k=\left(t_{r}-t_{o}\right) / t_{o}
$$

Where tr and to are the elution time and the column void time, respectively. The corresponding $1 / \mathrm{k}$ value obtained from data of $\mathrm{k}$ value was also calculated. In addition, the derived chromatographic values, i.e. S and $1 /$ ko obtained from the plots of $1 / \mathrm{k}$ vs. $\psi$ were also calculated on the basic of linear equation as shown in Eq. (6).

\section{RESULTS AND DISCUSSION}

\section{A. Dependency of Kon $\psi$ for $\beta$-Carotene as a Function of Temperature}

Under isocratic elution for $\beta$-carotene at 25 and $35{ }^{\circ} \mathrm{C}$ by changing the volume factions, $\psi(0 \% \leq \psi \leq 0.25 \%)$ of mobile phase compositions, the dependency of retention factor, $\mathrm{k}$ on $\psi$ for $\beta$-carotene was observed as shown in Fig. 2.

As evident from Fig. 2, the exponential dependencies of $\mathrm{k}$ values for $\beta$-carotene dramatically decrease with increasing in concentration of 2-propoanol in methanol and can be described by following equation:

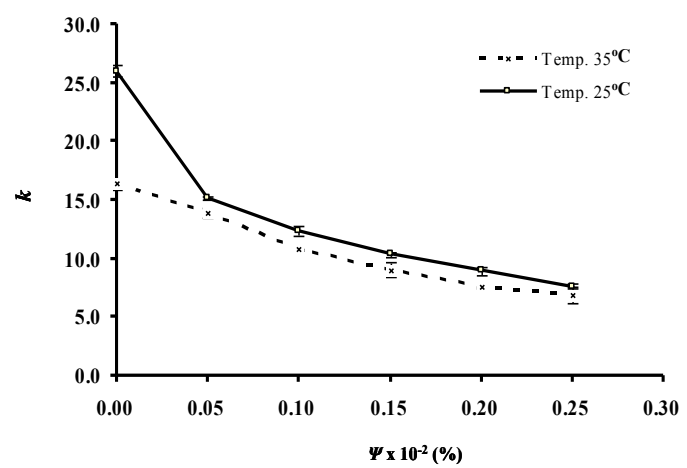

Figure2. Dependency values of $\mathrm{k}$ on $\psi$ of 2-propanol in methanol for $\beta$-carotene as a function of temperature by RP-HPLC. HPLC conditions are described in text.

$$
k=\mathrm{ae}^{-\mathrm{b} \psi}
$$

Where $a$ and $b$ are constants depending on volume fraction, $\psi$ of 2-propanol in methanol. It can be observed that the change in $\psi$ values from 0 to $0.25 \%$ resulted in faster elution of $\beta$-carotene. This is due to the increase in strength of mobile phases by increasing in 2-propanol concentration in methanol, in which its strength is directlyrelated to its polarity [5, 13-16].

From the observation, the different values of $a$ were found at 25 and $35^{\circ} \mathrm{C}$, and the difference was also found for the values of $b$ at these temperatures. Therefore, they were fitted to the following empirical exponential Eq. (3) and Eq. (4) according to the temperature at 25 and $35^{\circ} \mathrm{C}$, respectively.

$$
\begin{aligned}
& k=21.57 \mathrm{e}^{-4.52 \psi} \\
& k=16.08 \mathrm{e}^{-3.62 \psi}
\end{aligned}
$$

In the Eq. (3) and Eq. (4), the magnitudes of a and b obtained at $35 \mathrm{oC}$ are lower than those of their values obtained at $25 \mathrm{oC}$ resulting in faster elution of $\beta$-carotene. This dependency in reversed-phase system was essentially relating the interaction of $\beta$-carotene with immobilized n-alkyl chains in C-18 column during the chromatographic migration process. Then the $\mathrm{k}$ value can be related to the change in Gibbs free energy association $\left(\Delta \mathrm{G}_{\text {assoc }}^{\circ}\right)[1,2,15]$ for $\beta$-carotene and immobilized $n$ - 
alkyl chains binding. Therefore, the dependency of $\mathrm{k}$ on $\mathrm{T}$ can be represented as the following relationship [2]:

$$
\log k=-\Delta G_{a s s o c}^{\circ} / R T+\log \Phi
$$

Where $\mathrm{R}, \mathrm{T}$ and $\Phi$ are the universal gas constant (= $8.21 \times 10-2 \mathrm{~L} \cdot \mathrm{atm} / \mathrm{K} \cdot \mathrm{mol}$; atm $=101,325 \mathrm{~Pa})$, the absolute temperature $(\mathrm{K})$, and the phase ratio, respectively.

\section{B. Dependency of $1 / k$ on $\psi$ for $\beta$-carotene as a Function of Temperature}

Under similar experimental conditions as described above, the corresponding reciprocal retention factor, $1 / \mathrm{k}$ was calculated. The dependency of $1 / \mathrm{k}$ on $\psi$ for describing elution behavior of $\beta$-carotene at 25 and $35 \mathrm{oC}$ is plotted as shown in Fig 3.

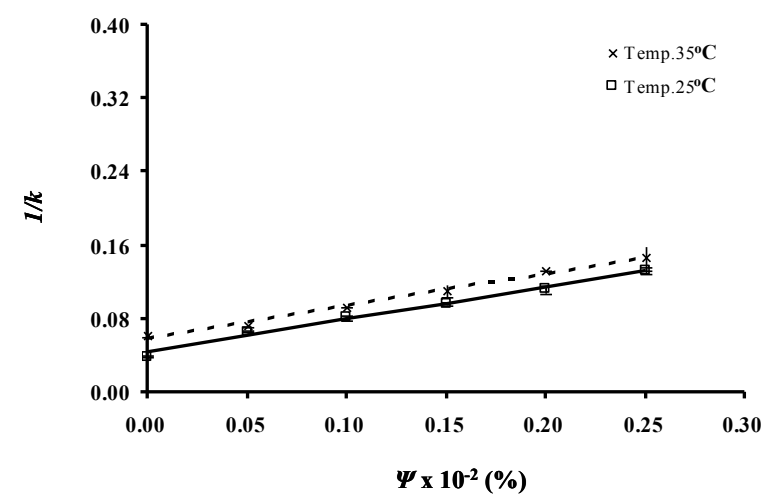

Figure3. Dependency values of $1 / \mathrm{k}$ on $\psi$ of 2 -propanol in methanol for $\beta$-carotene as a function of temperature by RP-HPLC. HPLC conditions are described in text.

It can be seen from Fig. 3 that a linear manner of the $1 / \mathrm{k}$ increases with increasing in concentrations of 2 propanol in methanol from 0 to $0.25 \%$ and the relationship between $1 / \mathrm{k}$ and $\psi$ values can be described by using Eq. (6).

$$
1 / k=S \psi+1 / k_{o}
$$

Where the $\mathrm{S}$ value is the slope and the $1 /$ ko values is $\mathrm{y}$ intercept. From the observation, the $S$ and $1 /$ ko values at 25 and 35 oC were different and they were also fitted to the following empirical linear Eq. (7) and Eq. (8) according to the temperature at 25 and $35 \mathrm{oC}$, respectively.

$$
\begin{aligned}
& 1 / k=0.337\left( \pm 2.16 \times 10^{-8}\right) \psi+0.046\left( \pm 1.18 \times 10^{-5}\right) \\
& 1 / k=0.371\left( \pm 4.33 \times 10^{-9}\right) \psi+0.055\left( \pm 5.12 \times 10^{-6}\right)
\end{aligned}
$$

As Eq. (7) and Eq. (8) have been considered, the larger values of $\mathrm{S}$ and $1 / \mathrm{ko}$ at $35 \mathrm{oC}$ were obtained resulting in shorter retention time of $\beta$-carotene, whereas the smaller values of $\mathrm{S}$ and $1 / \mathrm{ko}$ at $25 \mathrm{oC}$ were found resulting in longer retention time of $\beta$-carotene. This is due to the change in Gibbs free energy association for $\beta$-carotene and immobilized n-alkyl chains binging during the chromatographic migration process as mentioned earlier.

From the observation, the change of volume fraction, $\psi$ of 2-propanol from 0 to $0.25 \%$ in methanol strongly influenced to control the elution behavior of $\beta$-carotene by hydrophobic interactions between $\beta$-carotene and mobile phase. That is; their partition mechanisms were strongly increased with increasing in concentrations of 2propanol in methanol. In addition, the partition mechanism of $\beta$-carotene in mobile phases by 2 -propanol adding is better than those of pure mobile phase by 2propanol non-adding. That is; the more the concentrations of 2-propanol in methanol, the lower the retention of $\beta$ carotene, the partition of $\beta$-carotene into such mobile phases resulting in faster elution was obtained. This phenomenon can be attributed to the fact that the lower strength of mobile phase trends to be the lower retention with faster elution; the more the polarity and the less the strength of mobile phase, the less the retention of $\beta$ carotene with better hydrophobic interaction.

\section{Consideration of $S$ and $1 / k o$ Values for Retention Describing of $\beta$-carotene as a Function of Temperature}

Considering the plots of $1 / \mathrm{k}$ vs. $\psi$ in Fig. 3, the derived chromatographic values of slope, $\mathrm{S}$ and intercept, 1/ko are listed in Table I. The derived correlation coefficient values, $\mathrm{r} 2$ in agreement with linear dependency assuming under the relationships given by Eq. (7) and Eq. (8) are also listed in table 1 . In these equations, the $\mathrm{S}$ value is indicated the solvent strength of mobile phase, and the ko value is the retention factor of $\beta$-carotene in pure mobile phase $(100 \%$ of methanol or $\psi=0 \%$ of 2-propanol nonadding). The difference of $\mathrm{S}$ values indicates the change in $1 /$ ko with changing in solvent composition or $\psi$ values of mobile phases [11] which the hydrophobicity of $\beta$ carotene is strongly dependent on concentration of 2propanol as the organic modifier used.

TABLE I. DERIVATIVE ChromatographiC VALuES AND DERIVED CORRELATION COEFFICIENT FOR B-CAROTENE AS A FUNCTION OF TEMPERATURE

\begin{tabular}{llll}
\hline $\mathrm{T}\left({ }^{\circ} \mathrm{C}\right)$ & \multicolumn{2}{l}{$\begin{array}{l}\text { Linear dependencies, } \\
\text { under isocratic elution }\end{array}$} \\
\cline { 2 - 4 } & $\mathrm{S}$ & $1 / \mathrm{k}$ vs. & $\psi$ for $\beta$-carotene \\
\hline 25 & 0.337 & 0.046 & $\mathrm{r} 2$ \\
35 & 0.371 & 0.055 & 0.9783 \\
\hline
\end{tabular}

As the derived chromatographic data listed in table 1, it can be observed that the $\mathrm{S}$ and $1 /$ ko values obtained from the linear plot at $35 \mathrm{oC}$ are larger than those of the linear plot at $25 \mathrm{oC}$. That is; the more the temperature of pure mobile phase $(\psi=0 \%)$ at the same solvent strength, the less the retention of $\beta$-carotene, the faster elution was obtained. This phenomenon can be attributed to the fact that the higher temperature trends to be the faster elution with the higher change in Gibbs free energy association for $\beta$-carotene and immobilized n-alkyl chains binding during the chromatographic migration process as mentioned earlier. In this consideration, the higher r2 values to express the linear dependency from the plot at 35 oC were observed.

\section{Comparison Elution of $\beta$-carotene at Two Temperatures}

The proposed method was applied to the comparison of $\beta$-carotene elution using 2-propanol in methanol $(\psi=$ $0.25 \%$ ) at two temperatures used, i.e. 25 and $30^{\circ} \mathrm{C}$. It was 
found that the elution of $\beta$-carotene under such isocratic condition at $35^{\circ} \mathrm{C}$ was evidently faster than that of the elution at $25{ }^{\circ} \mathrm{C}$. Two chromatograms of $\beta$-carotene at those temperatures are shown in Fig 4.

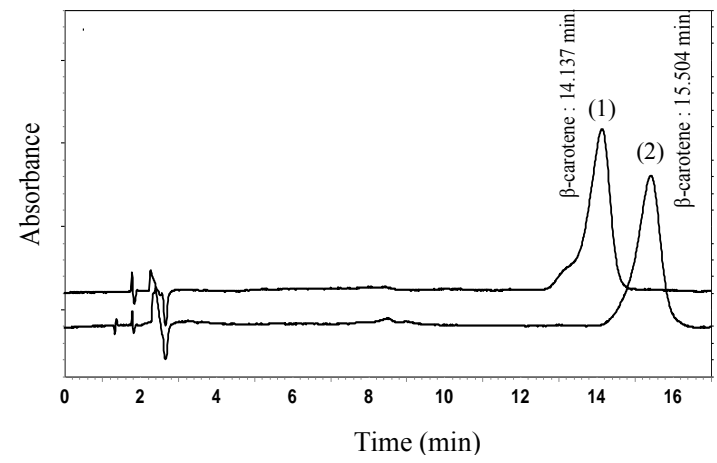

Figure4. Chromatograms of a $10-\mathrm{mg} / \mathrm{L} \beta$-carotene at $35^{\circ} \mathrm{C}(1)$ and 25 ${ }^{\circ} \mathrm{C}$ (2) with the elution using 2-propanol: methanol $(25: 75)$ at $\psi=0.25 \%$ by RP-HPLC. HPLC conditions are described in text.

\section{CONCLUSION}

The elution behavior of $\beta$-carotene under its partition between the binary mobile phases and immobilized nalkyl chains in stationary phase during the chromatographic migration process was depended on the polarity of mobile phase as a function of temperature used. That is; the mobile phase comprising 2-propanol in methanol at $\psi=0.25 \%$ was able to elute $\beta$-carotene successfully with the faster elution at $35 \mathrm{oC}$ evidently. Thus, these results will be useful for predicting and controlling its elution behavior under isocratic system.

\section{ACKNWLEDMENT}

Financial support granted by the Commission on Higher Education and research facilities provided by the Program of Chemistry, Faculty of Science and Technology, Songkhla Rajabhat University are gratefully acknowledged.

\section{REFERRENCES}

[1] P. Nikitas and A. Pappa-Louisi, "Retention models for isocratic and gradient elution in reversed-phase liquid chromatography," J. Chromatogr. A, vol. 1216, no. 10, pp. $1737-1755,2009$.

[2] A. W. Purcell, G. L. Zhao, M. I. Aquilar, and M. T. W. Hearn, "Comparison between the isocratic and gradient retention behavior of polypeptides in reversed-phase liquid chromatographic environments," J. Chromatogr. A, vol. 852, pp. 43-57, 1999 .

[3] E. Lessllier, C. West, and A. Tchapla, "Advantages of the use of monolithic stationary phases for modeling the retention in sub/supercritical chromatography application to cis/trans- $\beta$ carotene separation," J. Chromatogr. A, vol. 1018, pp. 225$232,2003$.

[4] P. Jandera, M. Holčapek, and L. Kolářová, "Retention mechanism, isocratic and gradient-elution separation and characterization of (co)polymers in normal-phase and reversed-phase high-performance liquid chromatography," $J$. Chromatogr. A, vol. 869, pp. 65-84, 2000.

[5] P. Jandera, L. Petránek, and L. Koláŕová, "Characterization and prediction of retention in isocratic and gradient-elution normal-phase high-performance liquid chromatography on polar bonded stationary phase with binary and ternary solvent systems," J. Chromatogr. A, vol. 791, pp. 1-19, 1997.

[6] T. Hagiwara, T. Yasuno, K. Funayama, and S. Suzuki, "Determination of lycopene, $\alpha$-carotene and $\beta$-carotene in serum by liquid chromatography-atmospheric pressure chemical ionization mass spectrometry with selected-ion monitoring," J. Chromatogr. B, vol. 708, pp. 67-73, 1998.

[7] H. Nyambaka and J. Ryley, "An isocratic reversed-phase HPLC separation of the stereoisomers of the provitamin A carotenoids ( $\alpha$ - and $\beta$-carotene) in dark green vegetables," $J$. Food Chem., vol. 55, pp. 63-72, 1996.

[8] J. Dulińska, et al., "Different effect of beta-carotene on proliferation of prostate cancer cells," Biochim. Biophys. Acta, vol. 1740, pp. 189-201, 2005.

[9] Q. Su, K. G. Rowley, and N. D. H. Balazs, "Carotenoids: Separation methods applicable to biological samples," $J$. Chromatogr. B, vol. 781, pp. 393-418, 2002.

[10] V. Rajendran, Y. S. Pu, and B. H. Chen, "An improved HPLC method for determination of carotenoids in human serum," J. Chromatogr. B, vol. 824, pp. 99-106, 2005.

[11] D. Thibeault, H. Su, E. MacNmara, and H. M. Schipper, "Isocratic rapid liquid chromatographic method for simultaneous determination of carotenoids, retinol, and tocopherols in human serum," J. Chromatogr. B, vol. 877, pp. 1077-1083, 2009.

[12] M. C. Aubert, et al., "Separation of trans/cis- $\alpha$ - and $\beta$ carotenes by supercritical fluid chromatography: I. Effects of temperature, pressure and organic modifiers on the retention of carotenes," J. Chromatogr. A, vol. 557, pp. 47-58, 1991.

[13] E. M. J. Verbruggen, H. C. Klamer, L. Villerius, U. A. T. Brinkman, and J. M. Hermens, "Gradient elution reversedphase high-performance liquid chromatography for fractionation of complex mixtures of organic micropollutants according to hydrophobicity using isocratic retention parameters," J. Chromatogr. A, vol. 835, pp. 19-27, 1999.

[14] F. Fitzpatrick, R. Edam, and P. Schoenmakers, "Application of the reversed-phase liquid chromatographic model to describe the retention behavior of polydisperse macromolecules in gradient and Isocratic Liquid chromatography," $J$. Chromatogr. A, vol. 988, pp. 53-67, 2003.

[15] J. Ko, J. Chilenski, T. Rodgers, and J. C. Ford, "Modeling the effect of solvation on solute retention in reversed-phase liquid chromatography," J. Chromatogr. A, vol. 913, pp. 15-22, 2001.

[16] Y. W. Lee, M. S. So, J. W. Lee, S. T. Chung, and K. H. Row, "Retention models of capacity factor with different compositions of organic modifier in RP-HPLC. Korean," $J$. Chem. Eng., vol. 13, pp. 578-584, 1996.

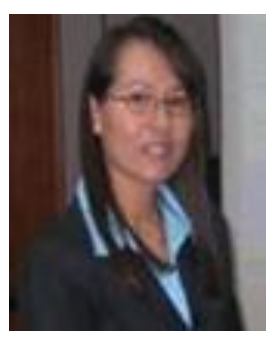

Charuwan Khamkaew was born in Pattani Province, Thailand. She got her B.Sc. (Chemistry), Ramkhamhaeng University, Bangkok, Thailand, 1989; M.Sc. (Analytical Chemistry), Prince of Songkla University, Songkhla Province, Thailand, 1995 Ph.D (Environmental Chemistry), University Science Malaysia, Penang, Malaysia, 2006. Now she is the Assistant Professor at Program of Chemistry, Faculty of Science and Technology, Songkhla Rajabhat University, Muang District, Songkhla Province 90000, Thailand. 